\title{
Mediastinal Solitary Fibrous Tumor
}

National Cancer Institute

\section{Source}

National Cancer Institute. Mediastinal Solitary Fibrous Tumor. NCI Thesaurus. Code C45744.

A localized neoplasm of probable fibroblastic derivation, that arises from the mediastinum. It is characterized by the presence of round to spindle-shaped cells, hylanized stroma formation, thin-walled branching blood vessels, and thin bands of collagen. 